\title{
Blood pressure measurements after mRNA-SARS-CoV-2 tozinameran vaccination: a retrospective analysis in a university hospital in France
}

\author{
Beatrice Bouhanick ${ }^{1,2}{ }^{凶}$, Clara Brusq ${ }^{3}$, Vanina Bongard (iD ${ }^{2,3}$, Samuel Tessier ${ }^{4}$, Jean-Louis Montastruc ${ }^{4,5}$, Jean-Michel Senard ${ }^{4,6}$, \\ François Montastruc ${ }^{4,5}$ and Fabrice Herin ${ }^{2,7}$
}

(c) The Author(s), under exclusive licence to Springer Nature Limited 2021

Journal of Human Hypertension (2022) 36:580-581; https://doi.org/10.1038/s41371-021-00634-0

\section{To the Editor:}

By July $22^{\text {nd }}, 202168$ million vaccine doses were administrated in France including 53 million of doses of tozinameran Comirnaty ${ }^{\circledR}$ vaccine (Pfizer/BioN-Tech) [1]. Before tozinameran was granted EU marketing authorisation, its efficacy and safety were assessed through pre-clinical studies and large clinical trials [2]. Despite a lack of signal during first clinical trials, reports of hypertension were found with this vaccine [2]. A case series of 8 patients with stage III hypertension after mRNA CoV-2 vaccine tozinameran, was recently published [3]. Between February and May 2021, several patients contacted the French Society of Hypertension to report either an increase in their blood pressure (BP) measures after vaccination or discovery of hypertension (data no shown). We have just published data extracted from Vigibase, the WHO pharmacovigilance database, showing that among 91,761 reports of adverse drug reactions involving Covid-19 vaccines, hypertension was reported in 1776 cases, mainly with tozinameran $(n=$ 1325; 75\%) [4].

In order to validate this signal, we retrospectively investigated BP profile of the vaccinated patients and healthcare workers who received tozinameran vaccine in Toulouse University Hospital from January $2^{\text {nd }}$ to April $23^{\text {rd }} 2021$. The aim of the study was to describe the course of blood pressure values after the first and the second injection of tozinameran and to assess the prevalence of high blood pressure values in this population. BP was measured 15 min after vaccine injection in all patients receiving a first or a second injection. Subjects were seated for $15 \mathrm{~min}$ after injection and before BP measurement. No measurement was done before injection. Measurements were performed with a validated automatic electronic device with European Community label (Carescape dinamap V100 GE medical system). If systolic BP(SBP)/ diastolic $B P(D B P)$ was below $140 / 90 \mathrm{mmHg}$, the subject underwent only one BP measurement. If BP was above $140 / 90 \mathrm{mmHg}$, another measurement was performed at least once and the last BP value was recorded in the data file. Hypertension was defined as BP greater than or equal to $140 / 90 \mathrm{mmHg}$. Grade III hypertension was declared if BP was greater than or equal to $180 / 111 \mathrm{mmHg}$. Categorical variables are described with numbers and percentages. Continuous variables are summarised with mean and standard deviation. Pearson's $x^{2}$ test was used to study associations between categorical variables and Mann-Whitney-test was used to compare mean age between hypertensive and nonhypertensive subjects. According to the French law, review from ethics committee is not required for such retrospective study.

23358 subjects received at least one dose of tozinameran vaccine of whom 21,909 had complete data on BP at the first visit (61.7\% were women, mean age was $59 \pm 20$ years). Among the 21,909 subjects, 8121 people (37.1\%) exhibited SBP and/or DBP above 140 and/or $90 \mathrm{mmHg}$ (high BP) after the first injection. Those with high BP after the first injection were older than those with normal BP (69 \pm 15 versus $53 \pm 20$ years); $46 \%$ were men versus $34 \%$ of those with normal BPs ( $p<0.001$ for both). 692 people (3.2\%) presented with grade III hypertension after the first injection. Again, subjects with grade III hypertension were older than those with normal BP $(74 \pm 13$ versus $58 \pm 20$ years) $(p<0.001)$. BP values are depicted in Table 1. Average time between two injections was $26 \pm 4$ days. Finally, among the subjects with high BP after the first injection and available BP measurements at the second visit, $64 \%$ were still hypertensive after the second one. Patients with high BP after both injections were older than those with high BP after the first one only $(71 \pm 14$ versus $67 \pm 16$ years. $p<0.001)$. $49 \%$ were men versus $44 \%$ of those with normal BPs after the second injection $(p<0.001)$; their initial BP after the first injection were higher than those of the patients who were hypertensive only after the first injection (SBP/DBP: $159 / 83 \mathrm{mmHg}$ versus $148 / 80 \mathrm{mmHg}$; $p<0.001$ ). Thirty-one percent of those with grade III hypertension after the first injection are still hypertensive at this stage after the second injection. Finally, $15 \%$ of the patients who were normotensive after the first injection had high BP after the second one.

Although $37 \%$ of subjects exhibited high BP 15 min after vaccine injection (slightly less after the second injection), this observed frequency is similar to that reported in the French

\footnotetext{
${ }^{1}$ Service d'Hypertension Artérielle et Thérapeutique, Centre Hospitalier Universitaire-Hôpital Rangueil, Toulouse, France. ${ }^{2}$ CERPOP, Université Paul Sabatier, INSERM, Toulouse,

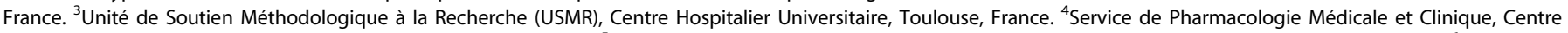

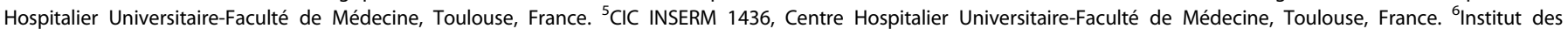

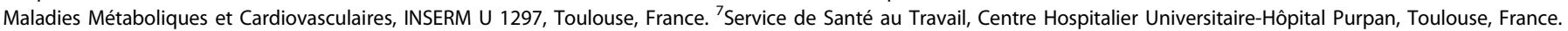
email: duly-bouhanick.b@chu-toulouse.fr
} 
Table 1. blood pressure values after the first and the second injection with tozinameran vaccine $(n=21,909)$.

\begin{tabular}{|c|c|c|c|}
\hline & & VISIT 1 & VISIT 2 \\
\hline \multicolumn{4}{|l|}{ All patients } \\
\hline PAS (mean \pm SD) & & $134 \pm 21$ & $133 \pm 21$ \\
\hline $\mathrm{PAD}($ mean $\pm \mathrm{SD})$ & & $75 \pm 11$ & $74 \pm 11$ \\
\hline \multirow{3}{*}{$\begin{array}{l}\text { Patients with } \mathrm{SBP} \geq 140 \text { and/o } \\
\mathrm{DBP} \geq 90 \mathrm{mmHg}(n / \%)\end{array}$} & YES & $8121 / 37.1$ & $4790 / 21.86$ \\
\hline & NO & $13788 / 62.9$ & $8801 / 40.17$ \\
\hline & MD & & $8318 / 37.97$ \\
\hline PAS (mean $\pm S D)$ & & $155 \pm 15$ & $155 \pm 15$ \\
\hline $\mathrm{PAD}($ mean $\pm \mathrm{SD})$ & & $82 \pm 11$ & $81 \pm 12$ \\
\hline \multirow[t]{3}{*}{ Grade I hypertension ( $n / \%)$} & YES & $5287 / 24.13$ & $3148 / 14.4$ \\
\hline & NO & $\begin{array}{l}16620 / \\
75.86\end{array}$ & $10557 / 48.2$ \\
\hline & MD & $2 / 0.01$ & $8204 / 37.5$ \\
\hline \multirow[t]{3}{*}{ Grade II hypertension ( $n / \%)$} & YES & $2121 / 9.68$ & $1209 / 5.5$ \\
\hline & NO & $\begin{array}{l}19786 / \\
90.31\end{array}$ & $12510 / 57.1$ \\
\hline & MD & $2 / 0.01$ & $8190 / 37.4$ \\
\hline \multirow[t]{3}{*}{ Grade III hypertension ( $n / \%)$} & YES & $709 / 3.24$ & $409 / 1.86$ \\
\hline & NO & $\begin{array}{l}21196 / \\
96.74\end{array}$ & $\begin{array}{l}13158 / \\
60.06\end{array}$ \\
\hline & MD & $4 / 0.02$ & $8342 / 38.08$ \\
\hline \multirow{3}{*}{$\begin{array}{l}\text { Isolated SBP among people } \\
\text { with high BP }(n / \%)\end{array}$} & YES & $5880 / 72.4$ & $3565 / 74.4$ \\
\hline & NO & $2236 / 27.5$ & $1207 / 25.2$ \\
\hline & MD & $5 / 0.1$ & $18 / 0.4$ \\
\hline
\end{tabular}

population from a same age range (55-64 years) (37.7\%), which is rather reassuring [5]. However, if the study suggests that the frequency of high BP is lower after the second injection than after the first one, almost two third of the patients with high BP after the first injection relapsed after the second one. Nevertheless, a white coat effect, a pain response in addition to a stress response due to the fear of injections cannot be excluded. Mechanisms underlying this rise in BP remain unknown. One could suggest an interaction between the S-protein and the renin-angiotensin system; an increase in sympathetic tone cannot be ruled out. Involvement of polyethylenglycol seems unlikely as BP increased too shortly after the injection.

The study has several limitations: the main one is the lack of prevaccination control of BP. History of hypertension of the patients is not reported and is another concern. Furthermore, we do not have home measurement of blood pressure values. Thus, the percentage of subjects with high BP we observed after vaccine injection may partially or totally correspond to unknown or previous known but insufficiently controlled hypertension. The lack of follow-up of the subjects with high BP is also a limitation as BP profile is not described. The main strength of the study is that it provides BP values in the immediate aftermath of vaccination, thus reflecting daily life. Systematic monitoring of BP faces organisational problems, and therefore is not implemented everywhere. Data on this topic are lacking. During the vaccination campaign in France, vaccinated subjects have to be monitored for 15-30 min after vaccination, mainly to look for an anaphylactic reaction, but systematic measurement of BP is not required. Further studies are required to fully interpret this signal in two distinct populations: normotensive people and hypertensive patients. While expecting them, we recommend monitoring BP in vaccinated patients focusing on vulnerable populations such as old patients, those with hypertension or those receiving antihypertensive drugs and, when they underwent the second injection, to pay attention to patients with high BP values after the first one. If BP remains above $180 / 110 \mathrm{~mm} \mathrm{Hg}$ or if the subject is symptomatic, people should be advised to attend their GP if necessary [6]. Anyway, it is important to underline that the present results do not allow to question in the study population the very favourable benefits-harms balance of Covid-19 vaccination, especially in patients with complicated hypertension.

\section{REFERENCES}

1. Point de situation sur la surveillance des vaccins contre la COVID-19-Période du 16/07/2021 au 22/07/2021. https://ansm.sante.fr/actualites/point-de-situation-surla-surveillance-des-vaccins-contre-la-covid-19-periode-du-16-07-2021-au-22-072021. Accessed Sep 2021.

2. European Medicines Agency. COVID-19 vaccine update. https://www.ema.europa eu/en/documents/covid-19-vaccine-safety-update/covid-19-vaccine-safetyupdate-comirnaty-18-june-2021_en.pdf. Accessed Aug 2021.

3. Meylan S, Livio F, Foerster M, Genoud PJ, Marguet M, Wuerzner G.on behalf of the CHUV COVID Vaccination Center. Stage III hypertension in patients after mRNAbased SARS-CoV-2 vaccination. Hypertension. 2021;77:e56-e57. https://doi.org/ 10.1161/HYPERTENSIONAHA.121.17316.

4. Bouhanick B, Montastruc F, Tessier S, Brusq C, Bongard V, Senard JM et al. Hypertension and Covid-19 vaccines: are there any differences between the different vaccines? A safety signal. Eur J Clin Pharmacol. 2021:1-2. https://doi.org/ 10.1007/s00228-021-03197-8.

5. Perrine AL. Hypertension in France: prevalence, treatment and management in 2015 and temporal trends since 2006. http://beh.santepubliquefrance.fr/beh/ 2018/10/2018_10_1.html. Accessed Aug 2021.

6. Point de situation sur la surveillance des vaccins contre la COVID-19-Période du 30/ 07/2021 au 19/08/2021. Actualité - Point de situation sur la surveillance des vaccins contre la COVID-19 - Période du 30/07/2021 au 19/08/2021 - ANSM (sante.fr). https://ansm.sante.fr/actualites/point-de-situation-sur-la-surveillance-des-vaccinscontre-la-covid-19-periode-du-30-07-2021-au-19-08-2021. Accessed Sep 2021.

\section{FUNDING}

The work was performed during the university research time of the authors using the database, which is available without fees in the department of the authors. Doctor François Montastruc has received funding under the Vigi-Drugs COVID-19 project from the French National Research Agency (ANR Agence Nationale de la Recherche) for the evaluation of pharmacovigilance data of drugs and vaccines used in the management or prevention of COVID-19. The other authors certify that they have not received any funding from any institution, including personal relationships, interests, grants, employment, affiliations, patents, inventions, honoraria, consultancies, royalties, stock options/ownership, or expert testimony related to this topic.

\section{AUTHOR CONTRIBUTIONS}

$B B, V B, F M$ and FH designed the study. VB, CB extracted the data from the database and performed the statistical analysis. All the authors analysed and discussed the data. All the authors reviewed the successive versions of the manuscript and approved the final version.

\section{COMPETING INTERESTS}

The authors declare no competing interests.

\section{ADDITIONAL INFORMATION}

Correspondence and requests for materials should be addressed to Beatrice Bouhanick.

Reprints and permission information is available at http://www.nature.com/ reprints

Publisher's note Springer Nature remains neutral with regard to jurisdictional claims in published maps and institutional affiliations. 